\title{
Hypernatraemia in Infants as a Cause of Brain Damage
}

\author{
DUNCAN MACAULAY and MARJORIE WATSON \\ From the Duchess of York Hospital for Babies, Manchester
}

When our experience of infants with hypernatraemic dehydration was reported 6 years ago from this hospital, the comment was made that, 'the follow-up period was, for many patients, too short to permit any evaluation of ultimate neurological status' (Macaulay and Blackhall, 1961). As far as we are aware no long-term studies of such patients have yet been published. This paper is a record of our attempts to discover the eventual neurological status of infants who had suffered from illnesses in which hypernatraemia had developed. The study was prospective, in that we started by identifying all patients recorded to have serum sodium levels of $150 \mathrm{mEq} / \mathrm{l}$. or above (the criterion used in our previous investigation) and then tried to trace them.

\section{Material and Methods}

Between October 1, 1957 and August 31, 1964 serum electrolytes were measured in 695 patients. While there is no established rule in the hospital, it can be taken that the principal reasons for asking for this investigation were to guide therapy in patients who required parenteral fluids and to assist in the diagnosis of obscure illnesses. In many patients repeated estimations were made and the figure of 695 does not reflect the actual load placed on the laboratory. Of the 695 patients, 122 were hypernatraemic, the serum sodium concentrations ranging from 150 to $235 \mathrm{mEq} / \mathrm{l}$. The illnesses for which these 122 children were admitted were diverse: 47 were suffering from diarrhoeal diseases; 13 had pneumonia; in 27 more than one disorder was present, e.g. a sickle-cell crisis in an infant with pneumonia; in the remaining 35 the diagnoses ranged widely-from meningitis to appendix abscess. The age range was from 1 day to 21 years.

The follow-up investigation was carried out in 1965-66 and occupied the greater part of one year. The minimum interval from the original admission to followup examination was $1 \frac{1}{2}$ years; the longest was more than 8 years. Intensive efforts were made to obtain information about every patient in the series. If contact could not be established by letter or personal visits to the lastknown address, attempts were made to find the families by inquiries addressed to family doctors, medical officers of health, health service executive councils, education authorities, the medical records departments of the armed forces, the Registrar General, etc. Some

Received December 19, 1966. patients whose families had moved around the country were traced after months of detective work. In spite of these efforts we were unable to get information about 6 of the children. Two were the offspring of immigrant parents who, we think, had returned to their native countries. One family was eventually traced but persistently refused to co-operate. In 3 cases the families had moved several years ago without leaving forwarding addresses and all attempts to discover their whereabouts failed.

Twenty-seven children had died-some as the result of the original illness, others from unrelated diseases long after the initial admission. Reports of necropsies were available for 24 of the 27 ; in one other we were unable to obtain the necropsy report: however, in this case detailed neurological investigation had been carried out, and the state of the nervous system was well documented; in 2 cases the parents had refused permission for necropsy.

Of the 89 known survivors, 14 were excluded from the main part of the survey because of neurological disorders known to have been present before the hypernatraemic episode. The diagnoses are listed in Table I.

Of the 75 children with whom we established contact, 62 attended for examination. Information about the 13 who could not attend-in almost all cases because of distance-was obtained from a number of sources. 4 of them had been placed for adoption by responsible agencies; it was not considered justifiable to approach

\section{TABLE I}

Conditions Antedating Development of Hypernatraemia and Leading to Exclusion from Main Part of Survey

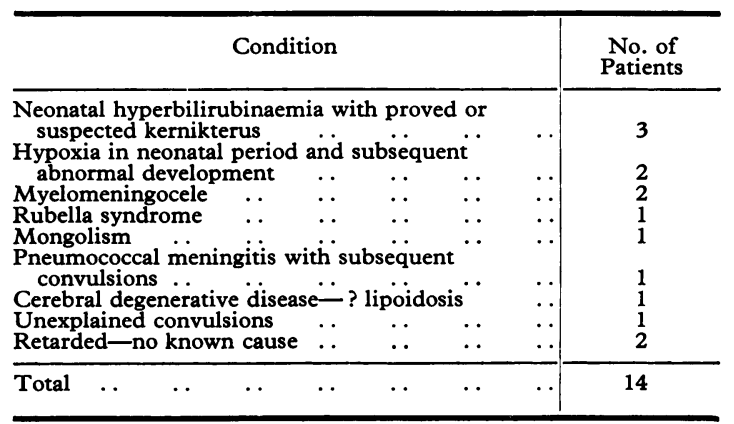


the adopting parents directly for fear of alarming them but the adoption societies reported that they were normal healthy children; all 4 were over the age of 5 years when inquiries were made. Five of the inaccessible children were known to school medical officers and teachers who provided information about themincluding the results of intelligence tests in 3 cases. For the other 4 we got reports from doctors-paediatricians and general practitioners-who knew them.

We consider that we have reliable information concerning all but 8 of the 122 children we tried to trace -the exceptions being the 2 fatal cases with no necropsy and the 6 untraced or uncooperative families. As there were also 14 children with pre-existing nervous disease we are left with 100 in whom an assessment of the effect of hypernatraemia can be attempted.

A full clinical examination was carried out, special attention being paid to the nervous system, and the results were recorded on a detailed form prepared for the purpose. Particular note was made of the history after the original illness, especially with regard to developmental progress, behaviour, and progress in school. Intelligence was measured by Valentine's 'Intelligence Tests for Children'. This is a satisfactory screening test but not sufficiently precise to justify recording the results in units. We therefore grouped the scores in decades and took the mid-point of each decade as the child's rating; e.g. a score of 85 indicates an IQ between 80 and 90 . This is accurate enough for our purpose and we found good agreement between our results and reports of school performance.

When we deemed a child to be abnormal a further opinion was obtained. We are grateful to Dr. N. S. Gordon, consultant paediatric neurologist, who examined all the patients we considered to have a neurological disorder and who advised us on the final diagnoses. We are also indebted to Miss Lenore Morton, electroencephalographer, who arranged special sessions for these patients.

\section{Results}

Table II shows the final classification of the 122 patients. The grounds for including patients in one or other of these categories are as follows.

Normal. All seen and examined. No history of neurological disturbance after the original illness. Satisfactory development progress. No abnormality on examination. IQ of 90 or above.

Probably normal. (a) The $\mathbf{4}$ adopted children (see above). (b) Eight children who were examined by us. In these the only unsatisfactory feature was an IQ between 80 and 90 . In 4, the family situation was unstable and we believe that the poor performance in intelligence tests was due to environmental factors and not to abnormality of the nervous system. Two others were making average progress in ordinary schools and their test scores probably did not reflect their actual abilities. The last two
TABLE II

Final Classification of 122 Patients

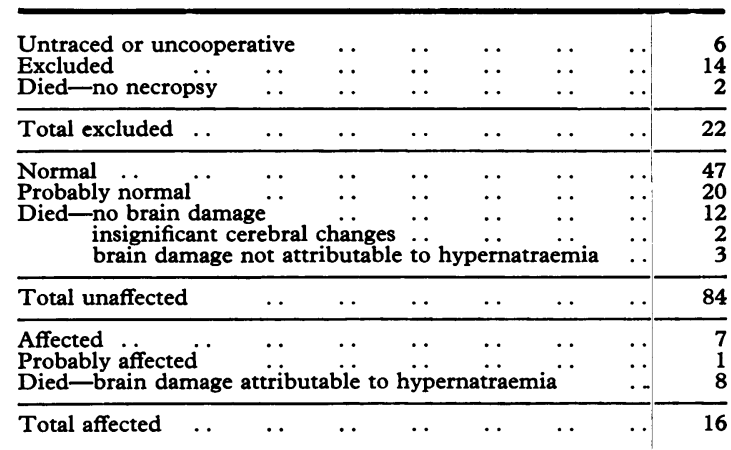

were extremely shy children who did not react well to the test situation. (c) Eight children for whom only reports from other sources were available. The comments made by school teachers and doctors who reported to us left little doubt that they considered the children to be healthy and intelligent. Since the opinions come from persons with professional training and experience in the supervision of children we accept them as reliable.

Dead-no brain damage. Post-mortem reports available for all. The causes of death were: pneumonia (3), malignant disease (2), heart disease (2), renal disease (2), cystic fibrosis, atelectasis, and renal and hepatic abnormalities of unknown origin ( 1 of each). 8 of the deaths occurred as the result of the original illness; the other 4 took place from 2 months to $1 \frac{1}{2}$ years later. Although the pathologists' reports stated specifically that the brains were normal, this is, of course, no guarantee that, had the patients survived, they would have developed normally. However, the findings in the cases with brain damage were so unequivocal that we do not hestitate to accept 'no brain damage' as a valid category.

Dead-insignificant cerebral changes. These 2 patients died of bronchopneumonia and, as part of a general state of congestion of the internal organs, congestion of the brain was noted.

Dead-brain damage not attributable to hypernatraemia. One of these 3 children had septicaemia with purulent meningitis. Another had been seen as an out-patient one week before admission and was then thought to have an unusually large head; necropsy revealed hydrocephalus. The third child died suddenly at home 3 months after 
TABLE III

Details of 'Affected' and 'Probably Affected' Patients

\begin{tabular}{|c|c|c|c|c|c|c|c|c|}
\hline \multirow{2}{*}{$\begin{array}{l}\text { Case } \\
\text { No. }\end{array}$} & \multicolumn{2}{|c|}{ Age at } & \multirow{2}{*}{$\begin{array}{l}\text { Neurological } \\
\text { Findings }\end{array}$} & \multirow{2}{*}{ IQ } & \multirow{2}{*}{$\underset{\text { Progress }}{\text { School }}$} & \multirow{2}{*}{ Behaviour } & \multirow{2}{*}{ EEG } & \multirow{2}{*}{ Diagnosis } \\
\hline & $\begin{array}{l}\text { Original } \\
\text { Illness }\end{array}$ & Follow-up & & & & & & \\
\hline 1 & $2 \mathrm{mth}$. & & Nil & 75 & Special & Maladjusted; & Normal & Cerebral \\
\hline 2 & $6 \mathrm{mth}$. & $2 \frac{1}{2} \mathrm{yr}$ & Spastic & $<50$ & $-^{\text {scnoor }}$ & Grossly & Generalized & Severe brain \\
\hline 3 & $3 \mathrm{mth}$. & $2 \frac{1}{2}$ yr. & $\mathrm{Nil}$ & * & & & Nil & Cerebral \\
\hline 4 & $5 \mathrm{mth}$. & $6 \frac{1}{2} \mathrm{yr}$ & Nil & 75 & Poor & $\begin{array}{l}\text { Backward; } \\
\text { clumsy; } \\
\text { hyperkinetic }\end{array}$ & $\begin{array}{l}\text { Epileptic } \\
\text { focus (L) } \\
\text { central }\end{array}$ & $\begin{array}{l}\text { Cerebral } \\
\text { dysfunction }\end{array}$ \\
\hline 5 & $3 \mathrm{mth}$. & 8 yr. & Nil & 60 & Poor & $\begin{array}{l}\text { Maladjusted; } \\
\text { retarded }\end{array}$ & $\begin{array}{l}\text { region } \\
\text { Nil } \\
\text { definite }\end{array}$ & $\begin{array}{l}\text { Cerebral } \\
\text { dysfunction }\end{array}$ \\
\hline 6 & $3 \mathrm{mth}$. & $\begin{array}{c}\text { Twin sister } \\
8 \neq \mathrm{yr} .\end{array}$ & $\begin{array}{l}\text { one year ahead at } \\
\text { Refractive }\end{array}$ & school an & $\begin{array}{c}\text { with normal } \\
\text { Special }\end{array}$ & EEG & Normal & Backward \\
\hline 7 & $5 \mathrm{mth}$. & $5 \mathrm{yr}$. & Nil & * & $-^{\text {school }}$ & $\begin{array}{l}\text { Backward; } \\
\text { clumsy; }\end{array}$ & Normal & $\begin{array}{l}\text { Cerebral } \\
\text { dysfunction }\end{array}$ \\
\hline $8+$ & $7 \mathrm{mth}$. & $6 \frac{1}{2}$ yr. & Nil (S.H.S.) & $60-70$ & Poor & $-^{\text {moody }}$ & - & Backward \\
\hline
\end{tabular}

* Untestable, but undoubtedly very backward. - No information, or not applicable. S.H.S. = School Health Service.

$t=$ Reports from school medical officer and teachers.

discharge from hospital, having apparently made a complete recovery from the original illness; necropsy showed the cause of death to be an acute diffuse, encephalopathy with cerebral congestion, scattered petechial haemorrhages throughout the brain, and foci of lymphocytic infiltration around some blood vessels. This was undoubtedly a 'cerebral' death but hardly attributable to the hypernatraemia which had apparently left the child unaffected.

Affected. The data for the 7 children in this group are summarized in Table III. The information we have about the 'probably affected' child is also shown.

In these cases particular inquiries were made about the pregnancy, delivery, neonatal period, and subsequent development; in all of them, as far as we could ascertain, the child had seemed quite normal before the hypernatraemic episode. Admittedly some of them were too young at the time of the illness to permit accurate assessment of their mental capabilities. This is a difficulty that would arise whatever the disorder being investigated, and there is no obvious way to overcome it. All we can say is that these apparently healthy infants became hypernatraemic at the ages shown and, after the intervals noted, had the disabilities listed. In the cases of the child with spastic tetraplegia and the girl with a twin sister as 'control' we believe the evidence is strongly in favour of the view that hypernatraemia caused their abnormalities. There seems to be no good reason for rejecting the hypothesis in the other cases.
Dead-brain damage attributable to hypernatraemia. The pathological findings in these cases are summarized in Table IV which also shows the reasons for including the child whose necropsy report we could not obtain. The same principles were applied as in the 'affected' group, i.e. the children were by all accounts in good health until the onset of the fatal illness. In all cases death was attributed by the pathologists to brain damage, and this in turn appeared to date from the illness in which hypernatraemia occurred. Death took place within 1 week of admission in 4 cases, within 1 month in 2, and $2 \frac{1}{2}$ and 3 months after admission in the remaining 2 . In these latter patients severe brain damage was clinically apparent throughout the prolonged terminal illness.

\section{Analysis and Discussion}

Association between brain damage and hypernatraemia. As noted above, we have reliable information about the fate of 114 of the 122 patients we started with. In 33 of the 114 brain damage was demonstrated at necropsy or inferred from clinical evidence. Table $\mathrm{V}$ shows that these 33 are almost equally divided between patients with pre-existing or unrelated cerebral pathology and those whose abnormalities could be attributed to hypernatraemia. This means that the undoubted association between hypernatraemia and brain damage-their concurrence in $30 \%$ of these patients is very unlikely to be due to chance-may indicate either a liability to cerebral damage from the electrolyte disturbance or the possibility of hyper- 
TABLE IV

Details of Cerebral Pathology 'Attributable to' Hypernatraemia

\begin{tabular}{|c|c|c|c|}
\hline Case No. & Gross Pathology & Histology & Diagnosis \\
\hline 9 & $\begin{array}{l}\text { Vessels congested; ventricles } \\
\text { dilated; petechil haemorrhages }\end{array}$ & Focal necrosis at many sites; & Diffuse encephalopathy \\
\hline 10 & $\begin{array}{l}\text { Vessels congested; small foci of } \\
\text { softening and haemorrhage }\end{array}$ & As in No. 9 & Diffuse encephalopathy \\
\hline 11 & $\begin{array}{l}\text { Vessels congested; areas of } \\
\text { necrosis in R. parietal and } \\
\text { L. occipital lobes }\end{array}$ & $\begin{array}{l}\text { Multiple foci of necrosis with } \\
\text { calcification }\end{array}$ & Diffuse encephalopathy \\
\hline 12 & No gross changes & $\begin{array}{l}\text { Areas of infarction with cell } \\
\text { necrosis }\end{array}$ & Cerebral infarction \\
\hline 13 & $\begin{array}{l}\text { Congestion and dilatation of } \\
\text { vessels; oedema }\end{array}$ & Cerebral oedema & Cerebral oedema \\
\hline 14 & $\begin{array}{l}\text { Intense congestion; massive } \\
\text { haemorrhage in middle fossa }\end{array}$ & Report lost & $\begin{array}{l}\text { Subarachnoid } \\
\text { haemorrhage }\end{array}$ \\
\hline 15 & $\begin{array}{l}\text { Extensive sinus thrombosis; } \\
\text { massive necrosis of both } \\
\text { hemispheres }\end{array}$ & $\begin{array}{l}\text { Extensive necrosis with softening } \\
\text { and cyst formation; organizing } \\
\text { thrombus in sinuses }\end{array}$ & Sinus thrombosis \\
\hline 16 & \multicolumn{3}{|c|}{$\begin{aligned} & \text { No necropsy report available (Coroner's post-mortem report) } \\
& \text { Before death = } \text { AEG showed dilatation of ventricular system } \\
& \text { EEG showed generalized dysrhythmia } \\
& \text { Clinical examination = spastic diplegia } \\
& \text { Neurological opinion = cerebral vascular thrombosis }\end{aligned}$} \\
\hline
\end{tabular}

natraemia being of neurogenic origin. There is some debate (Gilbert and Glaser, 1961; Pleasure and Goldberg, 1966) about the existence of 'neurogenic hypernatraemia' as an entity, distinct from disturbances in water balance from inadequate fluid intake due to impaired consciousness, ill-advised intravenous therapy in helpless patients, and acquired diabetes insipidus. Whatever the mechanism, there is no question of the frequency with which cerebral disease is associated with hypernatraemia (Cooke and Ottenheimer, 1960). This may be a source of great difficulty in the clinical situation where a patient is hypernatraemic and has evidence of a cerebral disorder. It is often impossible to decide immediately which is the primary disturbance. Indeed a decision may not be possible until all the data are available, perhaps in retrospect when the patient has died or recovered. Because of this it would be difficult to assess the effects of variations in treatment given early in the illness. Claims that one regimen is superior to others should be supported by statistical evidence based on groups of comparable patients treated in different ways. To the best of our knowledge no such evidence has been published and the treatment of hypernatraemic infants remains a matter of opinion.

\section{TABLE V}

Association Between Hypernatraemia and Brain Damage

\begin{tabular}{lllll}
\hline Patients for whom reliable information is available & \multicolumn{1}{l}{114} \\
\hline Brain damage & $\ldots$ & & $33(29 \%)$ \\
Antedating or unrelated to hypernatraemia & $\ldots$ & 17 \\
Attributed to hypernatraemia & $\ldots$ & $\ldots$ & $\ldots$ & 16 \\
\hline
\end{tabular}

Factors concerned in development of brain damage. We have examined our data to try to find factors in the original illness, which might be of aetiological or prognostic significance. Among the items examined were the patient's age and sex, the nature of the illness, the degree of the hypernatraemia, and the severity of early neurological disturbances. The only one that appears to be significant is the last.

To facilitate analysis numerical values have been given to the recorded neurological abnormalities, in the following manner.

$0:$ no record of any neurological symptoms or signs.

1: the presence of muscular rigidity or severe hypotonia or a convulsion or impaired consciousness.

2: a record of any two of the above signs or one of them plus a lumbar puncture (which would indicate concern about the neurological state greater than might be deduced from the recorded signs).

3: all three of the above signs present or two of them plus a lumbar puncture.

These have been our main criteria in the assessment of a patient's condition but we have also had regard to the description of the child's state if it could not be accommodated in these categories, e.g. frequent tremors not amounting to convulsions were recorded in some patients and have been taken to be a significant sign. There is no doubt that all patients given a score of 3 had clear evidence of considerable cerebral disturbance, while those rated 0 had no appreciable neurological upset The intermediate grades are less easy to evaluate, but we have done our best to give an objective assessment 
of the evidence available. As noted above, we have excluded all patients with a history of antecedent nervous disease from this part of the analysis, and we have considered only symptoms and signs occurring within 3 days of the discovery of the hypernatraemia. In short, we are attempting to evaluate disturbances closely related in time to the hypernatraemic state.

Table VI shows the distribution of the 'affected' survivors and of the deaths attributable to hypernatraemic brain damage, according to the severity of the early neurological derangement. There is a clear gradient from 'no cerebral symptoms, very small risk of permanent brain damage' to 'severe cerebral symptoms, high risk of permanent injury'. If an infant passes through an illness in which hypernatraemia is found, without showing any sign of cerebral disturbance, his chances of complete recovery are excellent. If he develops generalized muscular rigidity or marked hypotonia, with convulsions and impairment of consciousness, the chances of complete recovery, as far as the brain is concerned, are, according to our data, less than $50 \%$.

\section{TABLE VI}

Diagnosis of Initial Disease in Entire Series and in Patients who Sustained Brain Damage

\begin{tabular}{|c|c|c|c|c|}
\hline \multicolumn{3}{|c|}{ Diagnoses } & Whole Series & 'Cerebral' Cases \\
\hline $\begin{array}{l}\text { Diarrhoeal dis } \\
\text { Pneumonia } \\
\text { Multiple .. } \\
\text { Miscellaneous }\end{array}$ & $\begin{array}{l}\text { se } \\
\cdots \\
\cdots \\
\cdots\end{array}$ & $\begin{array}{l}\cdots \\
\cdots \\
\cdots\end{array}$ & $\begin{array}{l}47(39 \%) \\
13(10 \%) \\
27(22 \%) \\
35(29 \%)\end{array}$ & $\begin{array}{l}7(43 \%) \\
3(19 \%) \\
2(13 \%) \\
4(25 \%)\end{array}$ \\
\hline Total & . & .. & $122(100 \%)$ & $16(100 \%)$ \\
\hline
\end{tabular}

Contrary to our expectations the actual serum sodium concentration did not appear to be of prognostic significance. Of the 73 patients in whom the levels lay between 150 and $159 \mathrm{mEq} / 1 ., 10$ sustained brain damage, while of the 27 in whom the concentration of sodium in the serum was 160 $\mathrm{mEq} / 1$. or higher, 6 were affected; $\mathrm{p}>0.3$. As shown in Table VI, the types of disease associated with hypernatraemia did not differ in the patients who suffered brain damage from those in the series as a whole. Neither the age at the time of the original illness, nor the age at follow-up affected the results significantly. We thought we might find more affected children in the over 5-year group than among the under- 5 group, because of the greater ease of examining and testing the former and the availability of school reports. However, the proportions of affected individuals in the two groups did not differ significantly; 2 of the 30 under-5's examined by us were affected and 5 of the 32 over5 's. With such small numbers the difference could easily be due to chance $(p=0 \cdot 5)$.

Cerebral pathology in hypernatraemia. In their review of the pathology in hypernatraemic patients, Cooke and Ottenheimer (1960) say, 'The characteristic finding is that of a severe haemorrhagic encephalopathy'. Our data on the fatal cases (Table IV) are in general agreement with this statement. Apart from the instance of acute cerebral oedema (Case 13), all the changes found at necropsy are compatible with intracranial vascular damage. In the affected survivors the most common clinical finding was a state of generalized cerebral dysfunction, characterized by impairment of intellect, clumsiness, hyperactivity, and difficulties in social adjustment. It seems reasonable to regard the two sets of data as two sides of the same coin. If massive haemorrhage or thrombosis occurs in hypernatraemia death is likely to ensue (Table IV, Cases 14 and 15), but survival with severe disability is possible (Table III, Case 2). More commonly the pathological process is a diffuse encephalopathy with multiple small haemorrhages or thromboses. When children with this condition survive there may be no gross neurological deficit but evidence of a general cerebral dysfunction. That brain damage of this type can be caused by hypernatraemia seems convincingly demonstrated by the experimental observations of Finberg, Luttrell, and Redd (1957, 1959), and by reports of the pathological findings in accidental salt poisoning in infants (Finberg, Kiley, and Luttrell, 1963).

Not all hypernatraemic children who show conspicuous neurological signs suffer from haemorrhagic encephalopathy (Harrison and Finberg, 1964), and, in many, these disturbances may be the result of osmotic disequilibrium which may be entirely reversible. Some such explanation seems necessary to account for the $45 \%$ of infants with severe early symptoms who made complete recoveries (Table VII). Transient electroencephalographic abnormalities during hypernatraemia (Friis-

\section{TABLE VII}

\section{Relation Between Neurological Disturbances in} Original Illness and Eventual Status

\begin{tabular}{c|c|c|c|c}
\hline $\begin{array}{c}\text { Grade of } \\
\text { Neurological } \\
\text { Disturbance }\end{array}$ & Total & \multicolumn{3}{|c}{ 'Cerebral' Cases } \\
\cline { 2 - 4 } & & Alive & Dead & Total \\
\hline 0 & 41 & 1 & - & $1(2 \cdot 4 \%)$ \\
1 & 20 & 1 & - & $1(5 \%)$ \\
2 & 17 & 1 & 1 & $2(12 \%)$ \\
3 & 22 & 5 & 7 & $12(55 \%)$ \\
\hline
\end{tabular}


Hansen and Buchthal, 1965) would support this view.

It seems unlikely from our data that hypernatraemia is a common cause of gross neurological disease such as cerebral palsy. It may, however, contribute substantially to the numbers of backward and maladjusted children in the community. We calculate from official figures of paediatric admissions and population composition, that there may be about 1000 children of school age in England and Wales, whose educational and social difficulties could be attributed to the effects of hypernatraemia in infancy. If our data are representative (a supposition which we have no means of testing), approximately 100 deaths a year in the country may by due to severe hypernatraemic brain damage. If electrolyte estimations are not done many of these deaths are likely to be ascribed to encephalitis or intracranial haemorrhage. As a community concern the matter is far from negligible.

Implications. The figures in Table VII indicate that nearly $90 \%$ of the children who sustained brain damage showed signs of this injury within a short time of the detection of the hypernatraemia. Early neurological symptoms are therefore of potentially grave significance. It seems to us, on reviewing the records, that in several cases the damage had been done before treatment had a chance to affect the outcome. In Case 15 (Table IV) decerebrate rigidity followed repeated convulsions which started within an hour of admission to hospital. Prevention of hypernatraemia seems, therefore, to offer better prospects of reducing the incidence of brain damage than treatment of the established condition. In our first communication we commented on the importance of high fever, tachypnoea, and severe anorexia in the pathogenesis of hypernatraemia (Macaulay and Blackhall, 1961). These points are worthy of further emphasis. Any infant who is febrile and hyperventilating, whatever the cause, but especially if diarrhoea is present, needs more fluid than usual. The timehonoured allowance of $150 \mathrm{ml} . / \mathrm{kg}$. day represents the requirements of a healthy infant; in the circumstances mentioned, particularly in hot climates, it would not be excessive to offer twice this amount of fluid. If anorexia limits the intake steps must be taken to overcome this difficulty. Small frequent feeds-every 15 minutes if necessary-should be offered and some check made of the amount ingested. If the baby will not take the quantity of fluid he needs, tube-feeding or parenteral fluid administration must be resorted to. In this country this generally means that admission to hospital will be necessary.

The type of fluid offered is as important as the amount. 'The old ... practice of diluting feeding mixtures during illness should be revived' (Cooke and Ottenheimer, 1960). If a mother is advised to give her baby 'salt and water', precise instructions about concentration as well as quantity should be given, preferably in writing. We have recently seen an infant with mild diarrhoea whose mother was told to offer salt and water in place of the usual feeds, and who arrived at the hospital unusually limp and unresponsive; his serum sodium was 163 $\mathrm{mEq} / \mathrm{l}$. Fortunately he made a good recovery, as far as we can tell at present, but he might have sustained serious injury. 'Normal saline', which is much too concentrated for feeding to small babies, contains only 5 g. salt per pint. A tolerable concentration would be one-fifth to one-tenth of this strength, i.e. 0.5 to $1 \mathrm{~g}$. to the pint ( $600 \mathrm{ml}$.). Unfortunately domestic measures are quite unreliable for such small quantities. If an infant is to have solutions of electrolytes for administration at home the hospital practice of prescribing the fluid in accurately dispensed concentrations should be followed. In other words, these fluids, together with whatever drugs are ordered, should be obtained from a pharmacist.

\section{Summary}

An attempt has been made to determine the late effects of hypernatraemia in infancy by following up 122 children who were in hospital $1 \frac{1}{2}$ to 8 years previously and assessing their neurological condition. Of 100 who had no history of antecedent nervous disease, and who were traced, 16 were thought to have sustained brain damage; 8 were alive and 8 dead. Brain damage from hypernatraemia is probably of early onset in many cases, and prevention offers better hope of reducing its incidence than treatment of established hypernatraemia. Preventive measures are discussed.

We are grateful to the Friends of the Duchess of York Hospital for defraying the cost of this investigation. We wish to thank Professor W. F. Gaisford for reviewing the manuscript.

\section{REFERENCES}

Cooke, R. E., and Ottenheimer, E. J. (1960). Clinical and experimental interrelations of sodium and the central nervous system. Advanc. Pediat., 11, 81.

Finberg, L., Kiley, J., and Luttrell, C. N. (1963). Mass accidental poisoning in infancy. F. Amer. med. Ass., 184, 187. 
- Luttrell, C., and Redd, H. (1957). Functional, anatomical, and biochemical alterations of the brain resulting from experimental hypernatremic dehydration. Amer. F. Dis. Child., 94, 542.

$\longrightarrow$, and - (1959). Pathogenesis of lesions in the nervous system in hypernatremic states. II. Experimental studies of gross anatomic changes and alterations of chemical composition of the tissues. Pediatrics, 23, 46.

Friis-Hansen, B., and Buchthal, F. (1965). EEG findings in an infant with water intoxication and convulsions incident to hypernatraemia. Electroenceph. clin. Neurophysiol., 19, 387.
Gilbert, G. J., and Glaser, G. H. (1961). On the nervous system integration of water and salt metabolism. Arch. Neurol. (Chic.), 5, 179.

Harrison, H. E., and Finberg, L. (1964). Hypernatremic dehydration. Pediat. Clin. N. Amer., 11, 955.

Macaulay, D., and Blackhall, M. I. (1961). Hypernatraemic dehydration in infantile gastro-enteritis. Arch. Dis. Childh., 36, 543.

Pleasure, D., and Goldberg, M. (1966). Neurogenic hypernatremia. Arch. Neurol. (Chic.), 15, 78. 